\title{
Characteristics, Nutritional Status, and Sarcopenia in the Elderly in Pangkalpinang City
}

\author{
$1^{\text {st }}$ Ratmawati \\ Department of Nutrition \\ Health Polytechnic Pangkalpinang \\ Pangkalpinang, Indonesia \\ ummiranayumi@gmail.com
}

\author{
$2^{\text {nd }} \mathrm{S}$. Fatimah-Muis \\ Department of Nutrition Science \\ Faculty of Medicine, Diponegoro \\ University \\ Semarang, Indonesia \\ sitifatimahmuis@gmail.com
}

\author{
$3^{\text {rd }}$ Muchlis Achsan Udji Sofro \\ Department of Internal Medicine \\ Faculty of Medicine, Diponegoro University \\ Semarang, Indonesia \\ muchlis.aus@gmail.com
}

\author{
$4^{\text {th }}$ Ani Margawati \\ Department of Nutrition \\ Science Faculty of Medicine \\ Diponegoro University \\ Semarang, Indonesia \\ animargawati@gmail.com
}

\author{
$5^{\text {th }}$ Martha Irena Kartasurya \\ Faculty of Public Health \\ Diponegoro University \\ Semarang, Indonesia \\ mkartasurya64@gmail.com
}

correspondent author: ummiranayumi@gmail.com

Characteristics of the elderly (gender, age, and occupational status) and nutritional status were risk factors for sarcopenia based on muscle mass index, muscle strength, and walking speed. Provide nutritional education about the factors that influence changes during the aging process to prevent decrease in muscle mass and physical function.

Keywords: Characteristics, elderly, nutritional status, sarcopenia.

\section{INTRODUCTION}

Sarcopenia (1989) was first known as loss of muscle mass, muscle function and quality that tends to occur in the elderly $\geq 60$ years [1]-[2]. Sarcopenia is a geriatric syndrome in elderly $\geq 60$ years are marked by a progressive loss of muscle mass, muscle strength, and physical ability so as to reduce quality of life and independence, till increase disability and mortality.1 Etiology of sarcopenia is multifactorial, divided into primers (physiology) and secondary (pathology) [3][4]. Primary sarcopenia is a phenomenon of loss of muscle mass and muscle function due to anabolic resistance associated with age. Secondary sarcopenia as a consequence of exposure to various factors ffecting muscles in the presence of catabolic processes [4]- [6] . Secondary sarcopenia is related to activity (bed rest, sedentary lifestyle), chronic diseases (organ failure, inflammatory factors, endocrine diseases) and nutritional status (inadequate energy and protein intake due to malabsorption, gastrointestinal disease, anorexia) [3],[4],[7]. 
Obesity sarcopenia is a double burden on the physically less active elderly because it can increase the risk of insulin resistance, dyslipidemia, heart disease, and metabolic diseases [1],[3],[4]. Sarcopenia is associated with functional disorders and disabilities that affect the quality of life and the ability to survive, so that appropriate intervention is needed [8]. The diagnosis of sarcopenia is determined by criteria of low of muscle mass, muscle strength, and physical ability in the elderly [4],[9]. Diagnosis of obesity sarcopenia based on fat-free mass index (FFMI), or appendicular skeletal muscle mass index (SMI) to height [3]. The International Working Group on Sarcopenia (IWGS) and the European Working Group on Sarcopenia in the Older people (EWGSOP) provide diagnostic criteria based on low muscle mass and muscle function [1],[3][4].[10]-[11].

The Asian Working Group for Sarcopenia (AWGS) used the EWGSOP approach plus several Asian perspectives in the diagnosis and study of sarcopenia due to differences in ethnicity, genetic makeup, body size, lifestyle and cultural background. The recommended approach of AWGS in sarcopenia research is to measure changes in muscle mass, strength and function, physical performance, status of frailty, activity instruments and daily activities [12][13]. Functional, biological and physical changes during the aging process can be biomarkers in clinical trials of sarcopenia [14].

The category of sarcopenia reflects its severity as a guide to appropriate clinical management namely presarcopenia, sarcopenia and severe sarcopenia according to the EWGSOP [5]. The presarcopenia stage is characterized by low muscle mass, without impacting muscle strength or physical performance. The stage of sarcopenia is characterized by low muscle mass, plus low muscle strength or low physical performance. Severe sarcopenia stage if muscle mass is low, muscle strength is low and physical performance is low [4]. Changes in age-related body composition are very important to consider in sarcopenia intervention [15]. The etiology of composition changes the body is affected by hormonal changes, inflammatory cytokines, oxidative stress, energy from food and lifestyle [16].

Measurement of muscle mass is one of the direct anthropometric assessments that depict elderly skeletal muscles with sarcopenia. Methods for assessing muscle mass include Dual-energt X-ray absorptiometry (DXA), BIA, anthropometry, magnetic resonance imaging (MRI), and computed tomography (CT). Magnetic resonance imaging and CT as a standard for estimating muscle mass by separating fat mass from other soft tissues. Dual-energy X-ray absorptiometry as an alternative to clinical research by scanning the entire body for minimizing radiation and differentiating fat, bone mineral density and lean tissues [1],[4],[10],[17][9]. Measurement of muscle strength and strength can use computerized pneumatic strength with one repetition maximum (1-RM) as the gold standard. Hand grip strength is also a gold standard that can be used to assess muscle strength in research and clinical practice [1],[4],[10],[9]. The HGS method is recommended by EWGSOP because it is easy to use, the cost is cheap and widely available [18]. Walking ability is measured by the short physical performance battery (SPPB) method, usual gait speed, timed get-upand-go test and stair climb power test [1],[4],[10],[17][9]. The method recommended by EWGSOP is SPPB and gait speed in the diagnosis of sarcopenia because easier to use [18].

Healthy individuals experience decrease in muscle mass is $1 \%$ per year between the ages of 20 and 30 years; slight changes in muscle mass, muscle power and muscle strength between ages 30 and 50 years; and accelerated age 50 years [1]. The Asian Working Group for Sarcopenia (AWGS) states the prevalence of sarcopenia in Asia ranging from $2.5 \%$ to $45.7 \%$ [2]. Vitriana et al (2016) showed that the prevalence of sarcopenia in the elderly (60-85 years) in Bandung based on the cut-off value of the AWGS recommendation is $9.1 \%$, whereas based on the cut-off value of the Taiwan population is $40.6 \%$, because there is not cut off value of elderly population in Indonesia [8].

The proportion of elderly continues to increase in Indonesia, in 2010 around 10\%; 2012 was the third largest Asian country in a population above 60 years (25 million), after China (200 million) and India (100 million); estimated at $13 \%$ by 2025 ; and $25 \%$ (100 million) in 2050 [19]. The Central Statistics Agency reported that in 2016 the proportion of elderly (> 60 years) in Bangka Belitung was $3.37 \%$, in Pangkal Pinang City $6.38 \%$ and in Girimaya District 0.9\% [20]. An increase in the proportion of the elderly is affected by an increased degree of health and well-being of the population, but because it is influenced by low physical activity and protein energy intake is not appropriate to the needs, sarcopenia [1],[8].

The development of multifactorial sarcopenia is influenced by physical (sedentary), genetic, metabolic changes, neuromuscular damage, loss of anabolic and anticabolic responses to changes in extracellular amino acid concentration, malnutrition, body mass index (BMI), low absorption of nutrients, inflammation, and abnormal increase in abnormalities. reactive oxygen species (ROS) [21]-[22],[12],[23]-[24]. Risk factors for sarcopenia including age, sex, nutritional status, heart disease, hyperlipidemia, alcohol consumption, and low protein or vitamin intake [3],[25]. Decreased mobility, falls and broken bones, duration of treatment in the 
hospital, disability, decreased independence are also risk factors that can reduce quality of life and cause death in the elderly [21].

The human body will experience extraordinary changes during the aging process, one of which is skeletal muscle loss after five decades of life, called sarcopenia [22]. Various factors such as age, sex, lifestyle and health status can influence strength muscle and physical performance. Before the age of 60 years, there are still opportunities for intervention to prevent a decrease in muscle mass or physical function. The correlation between muscle strength and physical performance varies by age category and is significant in the elderly group ( $\mathrm{p}<0.05$ ). The study based on the gait speed method shows that gender differences also affect, women have lower muscle strength and physical function. Women should pay more attention to functional decline during the aging process than men [25]. Sarcopenia as a geriatric syndrome is influenced by the nutritional status and health of the elderly based on the results of measurements of muscle strength and gait speed [25].

Changes in body composition are characteristic of the aging process which is associated with a decrease in skeletal muscle mass and an increase in fat mass. The nutritional status of obesity synergistically causes metabolic disorders and affects physical function especially in the elderly population of women in Asia [2]. The formulation of the problem of this study was how to describe the characteristics, nutritional status, and sarcopenia of the elderly in the Pangkalpinang City. The purpose of this study was to analyze the characteristics, nutritional status, and sarcopenia of the elderly in the Pangkalpinang City. It was hoped that the results of this study will be the basis for the development of further epidemiological research in the prevention of sarcopenia.

\section{Design, place and time}

\section{METHODS}

This observational study used a cross sectional design. The study was conducted in Girimaya Subdistrict, the working area of the Girimaya Health Center, Pangkalpinang City, October 2017 - May 2018.

\section{Study participants}

The subjects of the study were the elderly in the community who met the inclusion and exclusion criteria in Girimaya Subdistrict, the working area of the Girimaya Public Health Center in Pangkalpinang City. Girimaya District have five of Development Posts Integrated (Posbindu). Determination of the number of subjects and regions in a non random manner with a purposive sampling technique. The number of subjects was taken from five of Posbindu in five villages in Girimaya Subdistrict, based on the completeness of the data on the visit of the integrated development post. The number of subjects based on a sample size of 132 people.

Inclusion criteria: elderly aged 60-69 years; able to walk independently without assistive devices; not residing in an elderly institution; able to hold; and willing to be participant and cooperative. Exclusion criteria: Alzheimer's sufferers; diabetics, severe cardiovascular and muscular problems; and is undergoing hospitalization. Exclusion criteria were made based on study of Li CI et al (2015) and CruzJentoft et al (2010) which stated that chronic diseases including organ failure, inflammatory factors, endocrine disease, diabetes, hypertension, arthritis, and osteoporosis were related to low muscle strength and physical performance [26],[4].

\section{Ethical clearance}

Data was collected after obtaining approval from the Medical Research Ethics Commission (KEPK) FK UNDIP with certificate number 19 / EC / FK-RSDK / I / 2018. Previously, each subject was independently informed of study procedures, informed consent and signed the consent form.

\section{Types and methods of data collection}

The independent variables are characteristics (gender, age, work status) and nutritional status, while the dependent variable is muscle mass, muscle strength, walking speed.

Data collection by interview using a questionnaire; measurement of muscle mass using Bioelectrical Impedence Analysis (BIA), digital, body fat monitor FEP-103 (Oserio), by calculating muscle mass index through the ratio of muscle mass in kilograms divided by the square of height in meters (muscle mass $/ \mathrm{H}^{2}$ ); measurement of muscle strength with a hand grip dynamometer, digital, camry model (EH101), performed three times on the dominant hand and taken the highest value in a standing position; measuring walking speed for 6 minutes by the American Thoracic Society (ATS) procedure [27]. Mileage is calculated based on the subject's ability during that time period to determine the speed of walking in meters per second; analysis of food intake using the method of food recall $1 \times 24$ hours for 3 days not in a row, by recording the type and amount of food consumed in the past 24 hours (yesterday).

This study used the BIA method because it is reliable and easy to use; hand grip strength (HGS) is a gold standard and easier to use in research in the community; and gait speed because it is easier to use. 1 Indicators of muscle mass assessment (Men $<8.87$ $\mathrm{kg} / \mathrm{m} 2$ and Women $<6.42 \mathrm{~kg} / \mathrm{m}^{2}$ ), muscle strength (Men $<22.5 \mathrm{~kg}$ and Women $<14.5 \mathrm{~kg}$ ) and elderly 
walking speed $(\leq 1 \mathrm{~m} / \mathrm{s})$ based on the Taiwan population cut-off, because anthropometric characteristics and life expectancy resemble the elderly population in Indonesia with ethnic, genetic, body size, lifestyle and cultural background approaches [8],[12],[13].

\section{Processing and data analysis}

All data is processed through the process of editing, coding, and tabulation. Data analysis used univariate statistical software (variables of gender, age, weight, height, body mass index, muscle mass, muscle mass index, muscle strength, walking speed); and bivariate (variables of age, nutritional status with muscle mass index, muscle strength, and walking speed). Bivariate analysis using Pearson correlation test with a significance value of $p<0.05$. Analysis of data obtained using IBM SPSS Statistics version 21.

\section{RESULTS}

Girimaya District is one of the sub-districts located in the center of Pangkalpinang City. Consists of five villages in the working area of the Girimaya Public Health Center as a study location. The proportion of female sex is more than male. The number of elderly people aged 60-69 years was 677 men and 794 women. Most of the hilly terrain, there is a golf course as a means of community sports, the potential for farming, and there are watersheds. Economic potential includes trade (40\%), animal husbandry, fisheries and agriculture $(25 \%)$, tourism $(15 \%)$, as well as home industry and services (20\%) [21],[28].

Elderly is one of the targets of health promotion that must be improved health services. Posbindu or Posila usila has been implemented in five villages, as an effort to facilitate access to public health services [28].

\section{Characteristics of subjects}

The study subjects were elderly in the community aged between 60-69 years. Data has been taken (interviews) and measurements (anthropometry, muscle strength, walking speed) in January - February 2018. The frequency distribution of characteristics of the elderly in the community can be seen in Table 1 .
Table 1. Frequency Distribution of Subject Characteristics $(\mathrm{n}=132)$

\begin{tabular}{|c|c|c|}
\hline Variable & $\mathbf{n}$ & $\%$ \\
\hline \multicolumn{3}{|l|}{ Gender } \\
\hline Male & 34 & 25.8 \\
\hline Female & 98 & 74.2 \\
\hline \multicolumn{3}{|l|}{ Nutritional status (IMT) } \\
\hline Low $\left(<18,5 \mathrm{~kg} / \mathrm{m}^{2}\right)$ & 9 & 6.8 \\
\hline $\operatorname{Normal}\left(\geq 18,5-<24,9 \mathrm{~kg} / \mathrm{m}^{2}\right)$ & 56 & 42.5 \\
\hline Obese $\left(\geq 25 \mathrm{~kg} / \mathrm{m}^{2}\right)$ & 67 & 50.7 \\
\hline \multicolumn{3}{|l|}{ Occupational status } \\
\hline Work & 96 & 72.7 \\
\hline Male & 27 & 28.1 \\
\hline Female & 69 & 71.9 \\
\hline Not work & 36 & 27.3 \\
\hline Male & 7 & 19.4 \\
\hline Female & 29 & 80.6 \\
\hline \multicolumn{3}{|l|}{ Type of work } \\
\hline Male & 27 & 28.1 \\
\hline \multicolumn{3}{|c|}{$\begin{array}{l}\text { (gardening, climbing hills, cutting down trees, hoeing, builders } \\
\text { welders, jamb craftsmen, day laborers) }\end{array}$} \\
\hline Female & 69 & 71.9 \\
\hline \multicolumn{3}{|c|}{$\begin{array}{l}\text { (gardening, climbing hills, selling at the market, washing workers } \\
\text { draw water, selling various foods, caring for grandchildren } \\
\text { cleaning service, household activities) }\end{array}$} \\
\hline
\end{tabular}

The characteristics of the elderly consisting of age, weight, height, and body mass index can be seen in Table 2.

Table 2. Description of Subject Characteristics $(n=132)$

\begin{tabular}{|c|c|c|c|}
\hline Variable & $\bar{X} \pm \mathrm{SD}$ & Median & Min - Max \\
\hline Age (years) ${ }^{\mathrm{a}}$ & - & 63 & $60-69$ \\
\hline Weight $(\mathrm{kg})^{\mathrm{b}}$ & $58.7 \pm 11.8$ & - & $28.2-92.1$ \\
\hline Height $(m)^{b}$ & $1.5 \pm 0.1$ & - & $1.4-1.7$ \\
\hline $\begin{array}{l}\text { Body mass index } \\
\left(\mathrm{kg} / \mathrm{m}^{2}\right)^{\mathrm{b}}\end{array}$ & $25.3 \pm 4.6$ & - & $13.6-37.8$ \\
\hline
\end{tabular}

\section{Sarcopenia of subject}

Sarcopenia according to the European Working Group on Sarcopenia in Older People (EWGSOP) is a syndrome with a multifactorial condition characterized by loss of skeletal muscle mass, muscle strength and physical performance progressively at risk of experiencing physical disability, decreased quality of 
life, increased risk of falling, affecting independence and death [1]-[4]. The development of sarcopenia is influenced by physical activity (sedentary), genetics, metabolic changes, neuromuscular damage, loss of anabolic and anticatabolic responses to changes in concentration extracellular amino acids, malnutrition, body mass index (BMI), nutrient absorption, inflammation, and increased abnormal reactive oxygen species (ROS) [21]-[22],[12],[23]-[24].

Risk factors for sarcopenia include age, sex, heart disease, hyperlipidemia, alcohol consumption, and low protein or vitamin intake [3]. Decreased mobility, falls and broken bones, length of hospital stay, disability, $\overline{A g e}^{-}$ decreased independence, also a risk factor that can reduce quality of life and cause death in the elderly [21].

The frequency distribution of sarcopenia based on muscle mass index, muscle strength and walking speed of the elderly can be seen in Table 3 .

Table 3. Distribution of the Frequency of Sarcopenia in Subjects $(\mathrm{n}=132)$

\begin{tabular}{lll}
\hline Variable & $\mathbf{n}$ & $\%$ \\
\hline$\quad$ Muscle mass index $\left(\mathrm{kg} / \mathrm{m}^{2}\right)$ & & \\
Not sarcopenia (male: $\geq 8.87$; female: $\geq 6.42)$ & 132 & 100.0 \\
Sarcopenia & 0 & 0 \\
$\quad$ Muscle strength $(\mathrm{kg})$ & & \\
$\quad$ Normal (male: $\geq 22.5 ;$ female: $\geq 14.5)$ & 93 & 70.5 \\
Low & 39 & 29.5 \\
$\quad$ Walking speed $(\mathrm{m} / \mathrm{s})$ & & \\
Normal (male and female: $>1)$ & 38 & 28.8 \\
Low & 94 & 71.2 \\
\hline $\begin{array}{l}\text { Information: Cut-off values based on Taiwan Population indicators } \\
\text { [8],[13] }\end{array}$
\end{tabular}

Description of sarcopenia based on muscle mass, muscle mass index, muscle strength, and walking speed of the elderly can be seen in Table 4 .

Table 4. Description of the Sarcopenia of Subjects $(n=132)$

\section{Correlation Test}

The correlation test of age and nutritional status with the sarcopenia in elderly can be seen in Table 5 .

Table 5 Correlation Test for Age and Nutrition Status with Muscle Mass Index, Muscle Strength, Walking Speed

\begin{tabular}{|c|c|c|c|c|c|c|}
\hline \multirow{3}{*}{ Variable } & \multicolumn{6}{|c|}{ Sarcopenia } \\
\hline & \multicolumn{2}{|c|}{ Muscle mass index } & \multicolumn{2}{|c|}{ Muscle strength } & \multicolumn{2}{|c|}{ Walking speed } \\
\hline & $\mathrm{p}$ value & r value & $\mathrm{p}$ value & r value & $\mathrm{p}$ value & $\begin{array}{l}\mathrm{r} \\
\text { value }\end{array}$ \\
\hline $\operatorname{Age}^{\mathrm{a}}$ & $0.016^{*}$ & -0.209 & $0.010^{*}$ & -0.222 & $0.002 *$ & $\begin{array}{l}- \\
0.267\end{array}$ \\
\hline $\begin{array}{l}\text { Nutritional } \\
\text { status }^{\text {b }}\end{array}$ & $0.000 * *$ & 0.656 & 0.788 & -0.024 & 0.543 & $\begin{array}{l}- \\
0.053\end{array}$ \\
\hline
\end{tabular}

Information: ${ }^{\mathrm{a}}$ : Spearman correlation; ${ }^{\mathrm{b}}$ : Pearson correlation;

$\mathrm{p}$ value $<0.001 * *$ : very significant; $\mathrm{p}$ value $<0.05 *$ : meaningful; $\mathrm{r}$ value: correlation coefficient and correlation direction (positive or negative)

Table 5 explains that there is a significant relationship between the age of the elderly with the sarcopenia based on muscle mass index, muscle strength, and speed of walking $(p<0.05)$. The nutritional status of the elderly is also positively correlated with muscle mass index $(p=0,000)$.

\section{DISCUSSION}

\section{Characteristics of subjects}

Table 1 explains the elderly in the community with the most gender are women: 98 people $(74.2 \%)$. Gender is one factor that can affect muscle strength and physical performance of the elderly. Zeng et al (2016) study showed the influence of gender differences based on the gait speed method [25]. Women have lower muscle strength and physical function, so it is necessary to pay attention of functional decline during the aging process compared to men. The aging process in men occurs gradually, whereas women occur drastically after menopause [1],[25].

\begin{tabular}{|c|c|c|c|c|}
\hline Variable & $\bar{X} \pm \mathrm{SD}$ & Median & Min - Max & \multirow{6}{*}{$\begin{array}{l}\text { Table } 1 \text { also explains the category of elderly nutritional } \\
\text { status based on body mass index (BMI) which is the } \\
\text { most obese: } 67 \text { people }(50.7 \%) \text {. The risk of developing } \\
\text { obesity sarcopenia will increase with age if your diet } \\
\text { and lifestyle are not balanced. It is made clear that } \\
\text { obesity sarcopenia is double burden on the physically } \\
\text { tess active elderly because it can increase the risk of } \\
\text { insulin resistance, dyslipidemia, heart disease and } \\
\text { metabolic diseases [3]-[4]. Sarcopenia is associated } \\
\text { with functional disorders and disabilities that affect the } \\
\text { quality of life and ability to survive, so that appropriate } \\
\text { interventions are needed [8]. It is known from Table } 1 \text {, } \\
\text { there are } 96 \text { people }(72.7 \%) \text { still working and living }\end{array}$} \\
\hline Muscle mass $(\mathrm{kg})^{\mathrm{a}}$ & - & 35.1 & $22.7-53.6$ & \\
\hline Muscle mass index $\left(\mathrm{kg} / \mathrm{m}^{2}\right)^{\mathrm{b}}$ & $15.6 \pm 1.5$ & - & & \\
\hline Muscle strength $(\mathrm{kg})^{\mathrm{b}}$ & $19.6 \pm 7.3$ & - & $6.6-45.3$ & \\
\hline Walking speed $(\mathrm{m} / \mathrm{s})^{\mathrm{b}}$ & $0.9 \pm 0.2$ & - & $0.3-1.5$ & \\
\hline $\begin{array}{l}\text { Information: } X \text { : average; SI } \\
\text { distributed; b: normally distribu }\end{array}$ & andard de & on; a: no & mally & \\
\hline
\end{tabular}


independently. Physical activity carried out by the elderly every day is related to the type of work. Heavy physical activities such as gardening, climbing hills, cutting trees, hoeing, construction workers, welders, jamb craftsmen, day laborers, selling at the market, washing workers, draw water, selling various foods, caring for grandchildren, cleaning service; and moderate physical activities such as household activities (sweeping, mopping, cooking, shopping at the market and washing).

Table 2 explains the average age of the elderly is 63 years. Age is also one of the factors that can affect muscle strength and physical performance of the elderly. Zeng et al's (2016) study stated that correlation of muscle strength and physical performance varied according to age category and was significant in the elderly group $(\mathrm{p}<0.05)$ [25]. The average body mass index of the elderly is $25.3 \mathrm{~kg} / \mathrm{m}^{2}$ with the category of obesity. There was a significant association of BMI with sarcopenia based on muscle mass index ( $p<$ 0.001).

The body will experience extraordinary changes during the aging process, one of which is skeletal muscle loss after five decades of life, called sarcopenia [22]. Healthy people experience a decrease in muscle mass $1 \%$ between the ages of 20 and 30 years; slight changes in muscle mass, muscle power, and muscle strength between the ages of 30 and 50 years; then accelerated after the age of 50 years. 1 Before the age of 60 years, there is still a chance of preventing a decrease in muscle mass or physical function [25].

Sarcopenia as a geriatric syndrome is influenced by the nutritional status and health of the elderly based on the results of measurements of muscle strength and gait speed [25]. Changes in body composition are characteristic of the aging process which is associated with a decrease in skeletal muscle mass and an increase in fat mass. The nutritional status of obesity causes metabolic disorders and affects physical function especially in the elderly female population in Asia [2]. Asians have a higher percentage of body fat with central fat accumulation, so the risk of metabolic disease is higher than Caucasians. Wu et al's study in Korea, more than $75 \%$ of elderly people with central obesity sarcopenia, which increases with age $(\geq 65$ years) [2].

\section{Muscle mass and muscle mass index of subjects}

Table 3 explains the sarcopenia of elderly based on good muscle mass index (not sarcopenia): 132 people $(100 \%)$. The diagnosis of sarcopenia cannot be established. The physical activity status of elderly by the working category is $72.7 \%$ (see Table 1).

In this study $50.7 \%$ were nutritionally obese (see Table 1). The risk of increasing body fat mass can affect muscle mass, muscle strength and speed of walking with increasing age. Nutrient intake, especially protein, energy, essential amino acids (leucine) and vitamin D, are important factors in the management of sarcopenia to increase muscle mass in the elderly [7],[21],[29]. Table 4 explains the mean muscle mass of the elderly is $35.1 \mathrm{~kg}$ with a muscle mass index of $15.6 \mathrm{~kg} / \mathrm{m}^{2}$.

Identification of sarcopenia using Taiwan population cut-off, because anthropometric characteristics and life expectancy resemble the elderly population in Indonesia with ethnic, genetic, body size, lifestyle and cultural background [8],[13],[12]. The study of Vitriana et al (2016), which used the Taiwan population cut-off to determine the prevalence of sarcopenia in the elderly (60-85 years) in Bandung [8]. The study of Zeng et al, (2016) using the recommendation of the Asian Working Group for Sarcopenia (AWGS) in determining the criteria for muscle mass in the elderly [25]. The pathway for establishing a sarcopenia diagnosis of AWGS recommendations states that if one or both of the measurements of muscle strength and low walking speed is followed by measurement of muscle mass, if the results are normal then sarcopenia is not yet categorized and the process can be inhibited [13]. European Consensus The Working Group on Sarcopenia in Older People (EWGSOP) in 2010 stated the diagnosis of sarcopenia was determined by the criteria of low muscle mass, low muscle strength and low physical ability in the elderly [4],[9]. The sarcopenia category consists of the stages of presarcopenia, sarcopenia and severe sarcopenia characterized by low muscle mass [4].

Muscle mass measurement is one of the direct anthropometric assessments that depict elderly skeletal muscles with sarcopenia [1]. Age-related changes in body composition need to be considered in sarcopenia interventions [15]. Hormonal changes, cytokine inflammation, oxidative stress, energy intake and lifestyle are influential factors [16].

Measurement of muscle mass in the elderly uses Bioelectrical Impedance Analysis (BIA) because it is easy to do, non-invasive, relatively inexpensive and portable [15]-[16]. Asian ethnic research on the elderly community ( $\geq 65$ years) in Korea using BIA in the appendicular skeletal muscle mass assessment [15]. Zeng et al (2016) study using BIA to measure the body composition of the elderly in the Chinese community. The study of Daly et al, using Dual-energy X-ray absorptiometry (DXA) and computed tomography (CT) in measuring the muscle mass and fat of elderly women to compare the effects of a combination of exercise and protein intake. This method is more often used in clinical study [1],[25]. 


\section{Muscle strength of subjects}

Table 3 explains the sarcopenia of elderly based on normal strength muscle category: 93 people $(70.5 \%)$. In this study, $29.5 \%$ had decreased muscle strength. Table 4 explains the average muscle strength of the elderly is $19.6 \mathrm{~kg}$. Identification of sarcopenia is based on muscle strength in the elderly using a Taiwan population cut-off. The study of Vitriana et al (2016) who used the Taiwan population cut-off to determine the prevalence of sarcopenia in the elderly (60-85 years) in Bandung [8]. Zeng et al (2016) study using the recommendation of the Asian Working Group for Sarcopenia (AWGS) in determining the criteria of muscle strength in the elderly in China [25].

The study of Vitriana et al (2016), said that the main factors that affect the strength of the elderly hand-held are age, sex, total body fat, and fat-free mass. Age, sex, lifestyle and health status factors can influence the strength of muscle tone in the elderly [8]. Zeng et al (2016) study states that the correlation between muscle strength and physical performance varies according to age category [26]. The decrease in muscle strength is faster than the decrease in muscle mass, because a decrease in muscle quantity and muscle quality based on the sarcopenia life course model according to the World Health Organization (WHO) [30].Measurement of muscle strength in the elderly uses Hand Grip Strength (HGS) because it is a gold standard for assessing muscle strength in study and clinical practice [1],[4],[10],[9] The HGS method is recommended by EWGSOP because it is easy to use, the cost is cheap and widely available [18]. The study of Daly et al, using one repetition maximum (1-RM) at a higher cost to measure the muscle strength of elderly women [1].

\section{Walking speed of subjects}

Table 3 explains the walking speed of the low category occurred in 94 people (71.2\%). Age, gender, lifestyle and health status can influence the physical performance of the elderly. The correlation between muscle strength and physical performance varies by age category [25]. Elderly walking speed in 38 people $(28.8 \%)$ is still in the normal category.

Table 4 explains the average walking speed of the elderly is $0.9 \mathrm{~m} / \mathrm{sec}$. The study of Vitriana et al (2016) that uses the cut-off of Taiwan's population to determine the prevalence of sarcopenia in the elderly (60-85 years) in Bandung [8]. Zeng et al (2016) research uses the recommendation of the Asian Working Group for Sarcopenia (AWGS) in determining the criteria for elderly walking speed in China [25].

Measurement of physical function of the elderly based on walking speed for 6 minutes. Mileage is calculated from the ability of the elderly during that time period to determine the speed of walking in meters per second [8],[17],[11],[27]. Gait speed is one of the methods recommended by EWGSOP in the diagnosis of sarcopenia because it is easier to use [18] The study of Zeng et al (2016) who used a 6-minute walking test to measure elderly walking speeds in China. The study of Lennders et al, using the sit-to-stand time method to measure the walking speed of the elderly. This method cannot be applied for elderly people who cannot stand without using their arms [1],[25]. The results also showed that there was a significant correlation between elderly age and sarcopenia based on muscle mass index, muscle strength, and walking speed $(\mathrm{p}<0.05)$. The nutritional status of the elderly is also positively correlated with muscle mass index $(p=0,000)$.

Gender is one factor that can affect muscle strength and physical performance of the elderly. Zeng et al (2016) research shows the influence of sex differences based on the gait speed method [25]. Women have lower muscle strength and physical function, so it is necessary to pay attention to functional decline during the aging process compared to men. The aging process in men occurs gradually, whereas women occur drastically after menopause [1]. The risk of developing obesity sarcopenia will increase with age if your diet and lifestyle are not balanced. It is made clear that obesity sarcopenia is a double burden on the physically less active elderly because it can increase the risk of insulin resistance, dyslipidemia, heart disease and metabolic diseases [3]-[4]. A limitation in this study is that the analysis of other factors that influence the incidence of sarcopenia in community elderly has not been done.

\section{CONCLUSION}

The characteristics of the elderly (sex, age, and occupational status) and nutritional status are risk factors for sarcopenia based on muscle mass index, muscle strength, and walking speed. Provide nutritional education about the factors that influence changes during the aging process to prevent decrease in muscle mass and physical function as suggestion.

\section{ACKNOWLEDGMENT}

Provider of financial support from the BPPSDM Ministry of Health of the Republic of Indonesia based on the Decree of the Minister of Health of the Republic of Indonesia No HK.02.02 / HV / SK / 169/2016 on Participants in the Task for Learning Human Resources in Health and Recipients of the Education Cost for Learning Tasks in 2016, as well as nutrition workers and cadres at the Girimaya Public Health Center, Pangkalpinang. 


\section{REFERENCES}

[1] Naseeb MA, Volpe SL. Protein and Exercise in the Prevention of Sarcopenia and Aging. Nutr Res 2017;40. https://doi.org/10.1016/j.nutres.2017.01.001.

[2] Wu YH, Hwang AC, Liu LK, Peng LN, Chen LK. Sex Differences of Sarcopenia in Asian Populations: The implications in Diagnosis and Management. J Clin Gerontol Geriatr 2016;7:37-43. https://doi.org/10.1016/j.jcgg.2016.04.001.

[3] Deutz NEP, Bauer JM, Barazzoni R, Biolo G, Boirie Y, Bosy-Westphal A, et al. Protein Intake and Exercise for Optimal Muscle Function with Aging: Recommendations from the ESPEN Expert Group. Clin Nutr 2014;33:929-36. https://doi.org/10.1016/j.clnu.2014.04.007

[4] Cruz-Jentoft AJ, Baeyens JP, Bauer JM, Boirie Y, Cederholm T, Landi F, et al. Sarcopenia: European Consensus on Definition and Diagnosis. Age Ageing 2010;39:412-23. https://doi.org/10.1093/ageing/afq034.

[5] Little RD, Prieto-Potin I, Pérez-Baos S, Villalvilla A, Gratal P, Cicuttini F, et al. Compensatory Anabolic Signaling in the Sarcopenia of Experimental Chronic Arthritis. Sci Rep 2017;7:1-11. https://doi.org/10.1038/s41598-017-06581-6.

[6] Morley JE, Argiles JM, Evans WJ, Bhasin S, Cella D, Deutz NEP, et al. Nutritional Recommendations for the Management of Sarcopenia. J Am Med Dir Assoc 2010. https://doi.org/10.1016/j.jamda.2010.04.014.

[7] Vitriana V, Defi IR, Nugraha GI, Setiabudiawan B. Prevalensi Sarkopenia pada Lansia di Komunitas ( Community Dwelling ) Berdasarkan Dua Nilai Cut-Off Parameter Diagnosis Sarcopenia Prevalence in Community-dwelling Elderly Based on Two Cut-off Pints Diagnosis Parameters. Mkb 2016;48:164-70.

[8] Yu SCY, Khow KSF, Jadczak AD, Visvanathan R. Clinical Screening Tools for Sarcopenia and Its Management. Curr Gerontol Geriatr Res 2016;2016. https://doi.org/10.1155/2016/5978523.

[9] Kim HK, Suzuki T, Saito K, Yoshida H, Kobayashi H, Kato $\mathrm{H}$, et al. Effects of Exercise and Amino Acid Supplementation on Body Composition and Physical Function in Community-dwelling Elderly Japanese Sarcopenic Women: A Randomized Controlled Trial. J Am Geriatr Soc 2012;60:16-23. https://doi.org/10.1111/j.15325415.2011.03776.x

[10] Kim H, Park I, On L. Reliability and Validity of Gait Speed Test. J Exerc Nutr Biochem 2016;20:46-50.

[11] Chen LK, Liu LK, Woo J, Assantachai P, Auyeung TW, Bahyah KS, et al. Sarcopenia in Asia: Consensus report of the Asian working group for sarcopenia. J Am Med Dir Assoc 2014. https://doi.org/10.1016/j.jamda.2013.11.025.

[12] Chen LK, Lee WJ, Peng LN, Liu LK, Arai H, Akishita M. Recent Advances in Sarcopenia Research in Asia: 2016 Update From the Asian Working Group for Sarcopenia. J Am Med Dir Assoc 2016;17:767.e1-767.e7. https://doi.org/10.1016/j.jamda.2016.05.016.

[13] Cesari M, Fielding RA, Pahor M, Goodpaster B, Hellerstein M, van Kan GA, et al. Biomarkers of sarcopenia in clinical trials-recommendations from the International Working Group on Sarcopenia. J Cachexia Sarcopenia Muscle 2012;3:181-190. https://doi.org/10.1007/s13539-012-0078-2.

[14] Khanna V, Khanna HC. Sarcopenia 2017;5:2-5. https://doi.org/10.19080/OROAJ.2017.05.555655.

[15] Kim JH, Choi SH, Lim S, Kim KW, Lim JY, Cho NH, et al. Assessment of appendicular skeletal muscle mass by bioimpedance in older community-dwelling Korean adults. Arch Gerontol Geriatr 2014;58. https://doi.org/10.1016/j.archger.2013.11.002.
[16] Chen CY, Chang CI, Chen CY, Huang $\mathrm{KC}$, Wu CH, Hsiung CA, et al. Comparison of three BIA muscle indices for sarcopenia screening in old adults. Eur Geriatr Med 2013;4. https://doi.org/10.1016/j.eurger.2012.11.008.

[17] Liu LK, Lee WJ, Liu CL, Chen LY, Lin MH, Peng LN, et al. Age-related skeletal muscle mass loss and physical performance in Taiwan: Implications to diagnostic strategy of sarcopenia in Asia. Geriatr Gerontol Int 2013;13. https://doi.org/10.1111/ggi.12040.

[18] Beaudart C, Reginster JY, Slomian J, Buckinx F, Dardenne $\mathrm{N}$, Quabron A, et al. Estimation of sarcopenia prevalence using various assessment tools. Exp Gerontol 2015. https://doi.org/10.1016/j.exger.2014.11.014.

[19] Zalukhu ML, Phyma AR, Pinzon RT. Proses Menua , Stres Oksidatif, dan Peran Antioksidan 2016;43:733-6.

[20] Badan Pusat Statistik Kota Pangkalpinang. Kota Pangkalpinang dalam angka 2017 (proyeksi penduduk). 2017

[21] Bauer JM, Verlaan S, Bautmans I, Brandt K, Donini LM, Maggio M, et al. Effects of a Vitamin D and LeucineEnriched Whey Protein Nutritional Supplement on Measures of Sarcopenia in Older Adults, the PROVIDE Study: A Randomized, Double-Blind, Placebo-Controlled Trial. J Am Med Dir Assoc 2015. https://doi.org/10.1016/j.jamda.2015.05.021.

[22] Kim JS, Wilson JM, Lee SR. Dietary implications on mechanisms of sarcopenia: roles of protein, amino acids and antioxidants. J Nutr Biochem 2010. https://doi.org/10.1016/j.jnutbio.2009.06.014.

[23] Walston JD. Sarcopenia in older adults. Curr Opin Rheumatol 2012 https://doi.org/10.1097/BOR.0b013e328358d59b.

[24] Campins L, Camps M, Riera A, Pleguezuelos E, Yebenes JC, Serra-Prat M. Oral drugs related with muscle wasting and sarcopenia. A review. Pharmacology 2017. https://doi.org/10.1159/000448247.

[25] Zeng P, Han Y, Pang J, Wu S, Gong H, Zhu J, et al. Sarcopenia-related features and factors associated with lower muscle strength and physical performance in older Chinese: A cross sectional study Physical functioning, physical health and activity. BMC Geriatr 2016. https://doi.org/10.1186/s12877-016-0220-7.

[26] Li CI, Li TC, Lin WY, Liu CS, Hsu CC, Hsiung CA, et al. Combined association of chronic disease and low skeletal muscle mass with physical performance in older adults in the Sarcopenia and Translational Aging Research in Taiwan (START) study. BMC Geriatr 2015;15. https://doi.org/10.1186/s12877-015-0011-6.

[27] Crapo RO, Casaburi R, Coates AL, Enright PL, MacIntyre NR, McKay RT, et al. ATS statement: Guidelines for the six-minute walk test. Am J Respir Crit Care Med 2002. https://doi.org/10.1164/ajrccm.166.1.at1102.

[28] Dinas Kesehatan Provinsi Kepulauan Bangka Belitung. Dinas Kesehatan Kota Pangkalpinang. Pelaporan kesehatan lanjut usia di Dinas Kesehatan, PP dan KB Kota Pangkalpinang. 2017. 2016.

[29] Reginster JY, Beaudart $\mathrm{C}$, Buckinx $\mathrm{F}$, Bruyère $\mathrm{O}$. Osteoporosis and sarcopenia: Two diseases or one? Curr Opin Clin Nutr Metab Care 2016;19:31-6. https://doi.org/10.1097/MCO.0000000000000230.

[30] Mijnarends D. Sarcopenia : a rising geriatric giant 2016:169. 